\title{
La autonomía de la voluntad en el arbitraje y en la mediación. Jurisprudencia constitucional española y experiencias en el ámbito del consumo
}

\author{
Ramón Herrera de las Heras*
}

\begin{abstract}
RESUMEN
El artículo tiene por objeto el análisis del principio de autonomía de la voluntad como inspirador del arbitraje y de la mediación, basándose en el estudio de la jurisprudencia que en este sentido ha establecido el Tribunal Constitucional y en un análisis doctrinal sobre uno de los principios inspiradores del arbitraje puesto en relación con el Real Decreto 231/2008 por el que se regula el Sistema Arbitral de Consumo en España.
\end{abstract}

Arbitraje - mediación - vías alternativas a la jurisdicción

The autonomy on the will on the arbitration and mediation. Spanish constitutional jurisprudence and consumer law

\begin{abstract}
The article is analyzing the principle of autonomy as the inspirer of the Alternative Dispute Resolutions, based on the study of the Constitutional jurisprudence and doctrinal analysis on one of the guiding principles arbitration in conjunction with Royal Decree 231/2008 for regulating the Consumer Arbitration System in Spain.
\end{abstract}

Arbitration - mediation - alternative dispute resolutions

* Abogado, Doctor en Derecho, Profesor contratado de la Universidad de Almería, España. Mediador en materia de consumo de la Excma. Diputación Provincial de Almería, España. Correo electrónico: lasheras@ual.es. Este trabajo se ha realizado en el marco del proyecto de investigación DER 2009-12717 "La protección del consumidor" durante los años 2010 y 2011.

Artículo recibido el 30 de marzo de 2012 y aceptado para su publicación por el Comité Editorial el 15 de junio de 2012. 
El contenido de este trabajo de investigación tiene por objeto el estudio y análisis del principio de autonomía de la voluntad como inspirador del arbitraje y la mediación y la jurisprudencia que en este sentido ha establecido el Tribunal Constitucional, especialmente en materia de consumo en el derecho español. El interés que presenta el tema para mí es doble, por un lado como investigador del mundo del derecho y por otro como miembro del proyecto de investigación referido y mediador de consumo de la Excelentísima Diputación Provincial de Almería desde el año 2008, el mismo en el que se aprobó el Real Decreto 231/2008 por el que se regula el Sistema Arbitral de Consumo en España, todo ello en el marco del contrato de investigación sobre arbitraje entre la Universidad de Almería y el ente provincial. En este sentido intentaré realizar un análisis doctrinal y jurisprudencial sobre el principio de autonomía de la voluntad en el arbitraje y en la mediación de consumo, y por otro compartir unas reflexiones sobre mi experiencia como mediador, especialmente en aquellos casos en los que este principio ha estado presente en mi trabajo.

Es obligado hacer una breve referencia al marco general de protección de los consumidores en nuestro país, donde tiene su origen, sin duda, el arbitraje, puesto que se configura como un elemento esencial de garantía y protección de los consumidores. La Constitución española recogió un precepto específico dirigido a la protección de los consumidores, el artículo 51 de la misma. Es muy importante el lugar en el que el legislador ha querido colocar este artículo, puesto que se ubica dentro del Título I que trata de los derechos y deberes fundamentales, en su Capítulo III dentro de los principios rectores de la política social y económica. También el artículo 51 viene precedido de algunos artículos que protegen de forma especial a la juventud -art. 48-, a los disminuidos -art. 49- y a la tercera edad -art. 50-. Lo destacable en este caso es que entiende el legislador constituyente español que existe una necesidad de dotar de especial protección a algunos grupos sociales como los jóvenes, la tercera edad, o los que verdaderamente nos van a interesar en este trabajo, los consumidores.

Este es el tenor literal del artículo 51 de la Constitución española:

“1. Los poderes públicos garantizarán la defensa de los consumidores y usuarios, protegiendo, mediante procedimientos eficaces, la seguridad, la salud y los legítimos intereses económicos de los mismos.

2. Los poderes públicos promoverán la información y la educación de los consumidores y usuarios, fomentarán sus organizaciones y oirán a éstas en las cuestiones que puedan afectar a aquéllos, en los términos que la Ley establezca.

3. En el marco de lo dispuesto por los apartados anteriores, la Ley regulará el comercio interior y el régimen de autorización de productos comerciales”.

Quisiera destacar, en lo que al trabajo atañe, que es destacable, y en mi opinión muy acertada, la inclusión en el primer párrafo del artículo 51 de una mención expresa de la exigencia de que la defensa de los derechos de los consumidores y usuarios se lleve a cabo "mediante procedimientos eficaces". Si bien es cierto que algunos autores han criticado esta referencia expresa a la necesidad de un procedimiento eficaz para la defensa de los 
derechos de los consumidores y usuarios por considerarlo reiterativo e incoherente ${ }^{1}$, entendemos que es un acierto el haber destacado esta cuestión que no hace sino resaltar el carácter fundamental que las cuestiones procedimentales tienen en materia de protección a los consumidores ${ }^{2}$. Así, podemos señalar que el arbitraje y la mediación se configuran, efectivamente, como procedimientos eficaces de protección de los consumidores. Eficaces porque, como veremos más adelante, el arbitraje va a traer numerosas ventajas a los consumidores como son la celeridad en el proceso, la gratuidad, la participación de las asociaciones de consumidores o la seguridad jurídica. La mediación, por su parte, aportará la posibilidad de que sean las partes en conflicto las que, con la ayuda de un tercero, lleguen a un acuerdo sin necesidad siquiera de que ese tercero sea el que imponga la solución.

\section{INTRODUCCIÓN A LA RESOLUCIÓN EXTRAJUDICIAL DE CONFLICTOS EN ESPAÑA}

La primera ley específica en materia de arbitraje en España después de la Constitución española de 1978 fue la Ley 36/1988, de 5 de diciembre, que fue derogada por la Ley 60/2003, de 23 de diciembre, de arbitraje, que entró en vigor el 26 de marzo de 2004, que a su vez fue modificada por la Ley 11/2011, de 20 de mayo, de reforma de la Ley 60/2003, de 23 de diciembre, de Arbitraje y de regulación del arbitraje institucional en la Administración General del Estado ${ }^{3}$. La Ley de Arbitraje pretende ser una ley general aplicable, por tanto, íntegramente a todos los arbitrajes que no tengan una regulación especial; pero también supletoriamente a los arbitrajes que la tengan. Vuelve a partir del principio de autonomía de la voluntad ${ }^{4}$-nudo principal de nuestro trabajo y sobre el que más adelante nos

${ }^{1}$ Vid. Ruiz-Rico, J. J. y Contreras, M., “Artículo 51”, en Comentarios a la Constitución española, Alzaga, O. (dir). Ed. Edersa, Madrid, p. 398 y ss.

2 Así lo sostiene, entre otros, Bercovitz Rodríguez-Cano, A., cuando afirma que "la experiencia diaria demuestra que de nada sirve el reconocimiento de derechos a los consumidores si no se arbitran los procedimientos que por su sencillez y su accesibilidad y eficacia puedan hacer que la realización de aquellos derechos sea efectiva". Vid. Bercovitz Rodríguez-Cano, A. y Bercovitz Rodríguez-Cano, R., Estudios jurídicos sobre protección de los consumidores. Editorial Tecnos, Madrid 1987, p. 26.

${ }^{3}$ Si bien esta ley no introdujo novedad alguna respecto al tema principal de nuestro trabajo, la autonomía de la voluntad sí que realizó, como se señala en su exposición de motivos, aportaciones importantes en otras áreas del arbitraje como la de llevar a cabo una reasignación de las funciones judiciales en relación con el arbitraje, incrementar tanto la seguridad jurídica como la eficacia de estos con la intención de mejorar las condiciones para que definitivamente se asienten en España arbitrajes internacionales y el refuerzo del papel de las instituciones arbitrales, la modificación del nombramiento de los árbitros, abriendo el abanico de profesionales con conocimientos jurídicos y la reforma de la anulación y revisión del laudo. Para un estudio detallado de la Ley 11/2011 de 20 de mayo pueden consultarse, entre otros, Stampa, G., "La reforma de la ley de arbitraje", en Diario la Ley $\mathrm{N}^{\circ} 7725$, octubre 2011.

${ }^{4}$ A este respecto señala Burgos que "la ley de arbitraje 60/2003 aumenta el ámbito de la autonomía de la voluntad en materia de arbitraje. Resulta natural que si el arbitraje nace de un convenio, las partes sean dueñas del procedimiento y lo puedan configurar por acuerdo entre ellas, a la medida de la controversia, sin más exigencias que las de las normas imperativas que regulan la esencia del arbitraje". Vid. Burgos Ladrón de Guevara, J., "Naturaleza y ámbito del 
detendremos con mayor detalle y profusión-y establece como únicos límites al mismo y a la actuación de los árbitros el derecho de defensa de las partes, el principio de igualdad y contradicción, que se erigen en valores fundamentales del arbitraje como proceso que es. Señala el preámbulo de dicha Ley que "entre las que tienen especial relevancia las que dotan de contenido a las normas legales dispositivas de esta ley mediante la remisión, por voluntad de las partes, a la de una institución arbitral o al contenido de un reglamento arbitral. Así, esta ley parte en la mayoría de sus reglas de que debe primar la autonomía de la voluntad de las partes. Mas esa voluntad se entiende integrada por las decisiones que pueda adoptar, en su caso, la institución administradora del arbitraje, en virtud de sus normas, o las que puedan adoptar los árbitros en virtud del reglamento arbitral al que las partes se hayan sometido" 5 .

Posteriormente, la Ley 60/2003 fue complementada, en materia de consumo, por el Real Decreto 231/2008 por el que se regula el Sistema Arbitral de Consumo, actualmente en vigor en España que, como veremos, ha traído numerosas ventajas en dicho procedimiento.

Hemos de señalar que el arbitraje, lejos de ser un hallazgo o creación contemporánea o actual, es el sistema de resolución de conflictos histórico, y que por lo tanto hunde sus raíces en la Antigüedad, como en la Grecia clásica, y, en España, en la época liberal de principios del siglo XIX. Así, señalaba el propio Platón en la que muchos creen su última obra, Las Leyes, que "los primeros jueces serán los que el demandante y demandado bayan elegido de común acuerdo, a quienes el nombre de árbitro conviene mejor que el de jueces" 6 . Vemos pues cómo el principio de autonomía de la voluntad aparece en estas palabras del filósofo griego en un doble sentido: en primer lugar, dando la posibilidad a que dos partes diriman sus controversias a través de este sistema; en segundo lugar, permitiendo que sean las dos partes, demandante y demandado, de común acuerdo, las que señalen la persona que ha de actuar como árbitro.

Por otro lado, en España, la Constitución de $1812^{7}$-más conocida como La Pepa-, paradigma de la filosofía liberal que inspiraba nuestro país por entonces, hacía mención en tres de sus artículos al sistema extrajudicial de resolución de conflictos ${ }^{8}$. Así el artículo 280 de la Constitución de 1812 señalaba que "no se podrá privar a ningún español del derecho de terminar sus diferencias por medio de jueces árbitros, elegidos por ambas partes".

arbitraje en la Ley 60/2003. Asistencia judicial del arbitraje”, en Diario la Ley, 2273/2007. núm. 6745, sección doctrina, 28 jun. 2007 , p. 8

${ }^{5}$ Preámbulo Ley 60/2003 de arbitraje, Boletín Oficial del Estado núm. 309, 26 de diciembre de 2003.

${ }^{6}$ En la misma obra hace lo que hoy podría parecer un alegato a favor del arbitraje al señalar que "una sociedad no es tal si lo que concierne a sus tribunales no está arreglado como es debido, ya que el mayor bien no es la guerra ni la sedición sino la paz y la buena inteligencia entre sus ciudadanos. Para ello es necesario que el estadista cree sistemas que pongan remedio a los disensos, obligando a los particulares a observar ciertas reglas y previendo que un tercero zanje las disputas". Vid. Platón, Las Leyes. Ediciones Ibéricas.

${ }^{7}$ La Constitución de 1812, de la que el próximo año se celebra su bicentenario, ha sido muy aplaudida por su calidad y ansias de libertad. Se puede consultar en la página web del Congreso de los Diputados: http://www.congreso.es/constitucion/ficheros/historicas/cons_1812.pdf

${ }^{8}$ Para un estudio detallado del arbitraje en la Constitución de 1812 puede consultarse la obra La jurisdicción arbitral en la Constitución de Cádiz. Merchán Álvarez, A., "La jurisdicción arbitral en la Constitución de Cádiz", Materiales para el estudio de la Constitución de 1812, Cano Bueso, J. (ed.), Parlamento de Andalucía/Tecnos, Sevilla, 1989, pp. 465-479. 
Nuevamente esa doble vertiente inspira este artículo, si cabe aún con más contundencia, puesto que, además de señalar que el árbitro lo decidirán libremente las partes, en este caso se impedía que si ambas partes estaban de acuerdo no pudiesen dirimir sus disputas a través del arbitraje. En el artículo 281 de la misma Constitución de 1812 se establecía que "La sentencia que dieren los árbitros se ejecutará si las partes, al hacer el compromiso, no se bubieren reservado el derecho de apelar". Sin duda el legislador constitucional de la época entró en detalle cuando señaló la posibilidad de que, llegado el caso en el que las partes lo hubiesen expresado con anterioridad, podían reservarse el derecho de apelación, cosa que hoy día en España no es posible, excepto, como es lógico, en los casos de nulidad. Por último, el artículo 282 de la Constitución de 1812 señalaba que "El alcalde de cada pueblo ejercerá en él el oficio de conciliador, y el que tenga que demandar por negocios civiles o por injurias, deberá presentarse a él con este objeto". Por lo tanto, incluso se hacía mención a la conciliación o mediación, que como queda claro se convertía en una obligación previa a la presentación de una demanda por actos civiles e incluso penales. En nuestro sistema actual, como ahora estudiaremos, la mediación no es obligatoria en materia de consumo -aunque sí su ofrecimiento para que las partes puedan acogerse a ella como recoge el artículo 38 del Real Decreto 231/2008-. También, para aquellos que pretendían demandar por injurias, que se trata de ámbito penal, se exigía esa conciliación. Hoy, en casos excepcionales - "baber procedido el culpable a reparar el daño ocasionado a la víctima, o disminuir sus efectos, en cualquier momento del procedimiento y con anterioridad a la celebración del acto del juicio oral"- podrá realizarse esta mediación penal. Varios juzgados españoles ya están dando oportunidad a las víctimas de delitos - con penas de hasta seis años de cárcel- a entablar contacto con los autores de los mismos y a establecer, bajo control judicial y con asesoramiento letrado, cuál es el castigo más apropiado. Es lo que se ha venido a llamar la civilización del Derecho Penal ${ }^{9}$.

\section{La Autonomía de la voluntad en el arbitraje}

La autonomía de la voluntad es, como ya hemos señalado, el principio en torno al que gira la institución del arbitraje. Podemos definirla como el poder reconocido a toda persona para conformar libremente una relación jurídica, siempre que, como señala el artículo 1255 del Código Civil, no sea contraria a las leyes, a la moral ni al orden público. La autonomía de la voluntad, como defiende Maluquer, "siempre ha sido entendida como el poder de autodeterminación de la persona que marca su propia independencia y libertad y que le faculta en todo lo relativo a la disposición, uso y goce de sus propios derechos y facultades, $e$

${ }^{9}$ El objetivo del servicio es ofrecer un procedimiento de mediación en las distintas fases del proceso penal -instrucción, enjuiciamiento y ejecución-, en aras de que tanto la persona que ha sufrido el delito o falta como la que es denunciada, voluntariamente, y en el marco del proceso penal, cuenten con la posibilidad de participar activamente en la resolución del conflicto delictivo en el que están implicadas, con la intervención de una persona mediadora. 
incluso sobre la creación, modificación y extinción de los mismos" ${ }^{10}$. En una clásica formulación, De Castro la define como aquel poder complejo reconocido a la persona para el ejercicio de sus facultades, sea dentro del ámbito de libertad que le pertenece como sujeto de derechos, sea para crear reglas de conducta para sí y en relación con los demás, con la consiguiente responsabilidad en cuanto actuación en la vida social ${ }^{11}$.

Sin duda, el principio de autonomía de la voluntad está muy ligado al derecho dispositivo, uno de los pilares básicos del Derecho Civil ${ }^{12}$. Esto implica que igual que hay normas que solo serán aplicables en el caso en el que los sujetos no hayan ordenado sus relaciones de otra forma, también las habrá que se imponen necesariamente y no pueden ser ni eliminadas ni alteradas por los sujetos. Estas últimas, por lo tanto, no podrán ser objeto de arbitraje $\mathrm{e}^{13}$, y deberán ser expresamente indicadas por la ley. Por ejemplo, en materia de consumo esas excepciones se recogen el Real Decreto de 2008 en el que, a pesar de ser materias disponibles, excluye aquellas que estén unidas a otras indisponibles, como en las que haya de intervenir el ministerio fiscal y los casos en los que se produzca intoxicación, lesión, muerte o indicios de delito. Las materias dispositivas, en cambio y como regla general, sí que podrán ser objeto de arbitraje. De este modo, la Ley de Enjuiciamiento Civil señala que "los litigantes estén facultados para disponer del objeto del juicio y podrán renunciar, desistir del juicio, allanarse, someterse a arbitraje y transigir sobre lo que sea objeto del mismo, excepto cuando la ley lo probiba o establezca limitaciones por razones de interés general o en beneficio de tercero" "14. Así lo ha venido a confirmar el Tribunal Constitucional, aunque con una afirmación negativa, al señalar que “...quedan extramuros del arbitraje aquellas cuestiones sobre las cuales los interesados carezcan de poder de disposición..." 15 . De hecho, la potestad de los árbitros de llevar a cabo la resolución de controversias, sobre materias de libre disposición para las partes conforme a Derecho, encuentra precisamente su fundamento en la libertad y autonomía de la voluntad de los particulares, materializada en el convenio arbitral. ${ }^{16}$ El convenio arbitral se constituye como la pieza angular del arbitraje, pues deviene el fundamento y el límite del mismo. Sin convenio no hay arbitraje, pues en él las partes expresan su voluntad de someter un

10 "Con ello-continúa-se explica la autonomía como un poder de autorregulación de intereses propios que lleva a cabo el mismo titular y que le legitima para llevar a cabo la organización de sus compromisos a su plena libertad, en correspondencia a sus propios intereses y en el marco de la regulación establecida por el propio ordenamiento jurídico". Maluquer Montes, C., "Oferta pública de sometimiento al sistema arbitral”, en Estudios sobre consumo N ${ }^{\circ}$ 59, Madrid, 2001, p. 182.

${ }^{11}$ Cfr. De Castro, F., El negocio jurídico, Tecnos, Madrid, 1967, p. 11.

12 También lo es del arbitraje, puesto que, como señala el artículo 2.1 de la Ley 60/2003, "son susceptibles de arbitraje las controversias sobre materias de libre disposición conforme a derecho".

${ }^{13}$ Es evidente que el arbitraje, a pesar de nacer como una manifestación del principio de autonomía de la voluntad, no puede servir como solución a cualquier caso o controversia. Como señala Cremades, "el arbitraje nace como genuina manifestación de la autonomía de la voluntad y siempre dentro de los límites propios de su ejercicio, establecidos por el ordenamiento jurídico". Vid. Cremades, B., "Consolidación de la autonomía de la voluntad en España: El arbitral”, Tratado de derecho arbitral, Soto Coaguila, C.A. (dir.). Ed. Colección de Estudios, 2011. tomo I, p. 659.

${ }^{14}$ Artículo 19.1 de la Ley de Enjuiciamiento Civil.

${ }^{15}$ Vid. Auto del Tribunal Constitucional 259/1993.

${ }^{16}$ Cremades, B., "El arbitraje en la doctrina constitucional española", en la Ley 5432/2007, p. 1. 
determinado conflicto al arbitraje, con exclusión de la Jurisdicción ${ }^{17}$. Dicha autonomía de la voluntad adquiere, como afirma Fernández Rozas, un papel protagonista y sólo debe ceder ante ciertos preceptos de carácter imperativo o de obligada observancia por las partes que se contienen en la Ley de Arbitraje, preceptos que cada vez son menores y más reducidos como evidencia la redacción de la Ley de Arbitraje 60/2003 ${ }^{18}$.

Aunque la Constitución española de 1978 no haga mención alguna al arbitraje, como sí hemos visto que hacía la de 1812, el Tribunal Constitucional ha declarado en numerosas ocasiones, como ahora veremos, el encaje constitucional de este método de resolución extrajudicial de $\operatorname{conflictos}^{19}$. Ha señalado el Tribunal Constitucional en numerosas ocasiones que el arbitraje es un "medio heterónomo de arreglo de controversias que se fundamenta en la autonomía de la voluntad de los sujetos privados; lo que constitucionalmente le vincula con la libertad como valor superior del ordenamiento" ${ }^{20}$. El principio de autonomía de la voluntad es, sin duda alguna, el principio básico en torno al que gira el arbitraje y lo informa durante todo el procedimiento, así lo afirman tanto la Ley 60/2003 21 como la doctrina jurisprudencial del Tribunal Constitucional. Incidiendo en ello, me parecen esclarecedoras las palabras de Fernández Rozas cuando señala que "el arbitraje

${ }^{17}$ Vid. Bonachera Villegas, R., "El real decreto 231/2008, la anhelada modificación del sistema arbitral de consumo” en Diario la Ley, núm. 7045, octubre 2008.

${ }^{18}$ Sostiene este autor que "el dominio de las partes del procedimiento arbitral alcanza al hecho de que puedan consentir determinadas infracciones en el desarrollo del mismo siempre que afecten a aspectos dispositivos y de libre disposición". Vid. Fernández Rozas, J.C., "Arbitraje y jurisdicción: una interacción necesaria para la realización de la justicia”, en Derecho privado y Constitución, núm. 19, 2005, p. 59.

${ }^{19}$ Como concluye Otero Lastres, "si la Constitución de 1978 bubiera mencionado expresamente el arbitraje, como hacia la Constitución de Cádiz de 1812, el intérprete no se vería obligado a realizar todos estos esfuerzos para situar al arbitraje en el lugar que le corresponde dentro de la Constitución". Otero Lastres, J.M., "El derecho fundamental a la tutela judicial efectiva”, en Abogados, 2007, p. 55.

20 Así se recoge en la stc 176/1996, de 11 de noviembre, en su fundamento 4: "tal planteamiento, sin embargo, no puede ser compartido, ya que supondría tanto como privar al arbitraje, cuya licitud constitucional hemos declarado reiteradamente (sstc 43/1988 (rtc 1988\43), 233/1988 (rtc 1988\233), 15/1989 (rtc 1989\15), 288/1993 (rtc 1993\288) y 174/1995 (rtc 1995\174)), de su función como medio heterónomo de arreglo de controversias que se fundamenta en la autonomía de la voluntad de los sujetos privados; lo que constitucionalmente le vincula con la libertad como valor superior del ordenamiento (art. $1.1 \mathrm{ce}$ ). de manera que no cabe entender que, por el becho de someter voluntariamente determinada cuestión litigiosa al arbitraje de un tercero, quede menoscabado y padezca el derecho a la tutela judicial efectiva que la constitución reconoce a todos. una vez elegida dicha vía ello supone tan sólo que en la misma ha de alcanzarse el arreglo de las cuestiones litigiosas mediante la decisión del árbitro y que el acceso a la jurisdicción (pero no su "equivalente jurisdiccional" arbitral, sstc 15/1989, 62/1991 (rtc 1991\62) y 174/1995) legalmente establecido será sólo el recurso por nulidad del l.a. y no cualquier otro proceso ordinario en el que sea posible volver a plantear el fondo del litigio tal y como antes fue debatido en el proceso arbitral. pues como ha declarado reiteradamente este tribunal, el derecho a la tutela judicial efectiva no es un derecho de libertad, ejercitable sin más y directamente a partir de la constitución, sino un derecho prestacional, sólo ejercitable por los cauces procesales existentes y con sujeción a su concreta ordenación legal (sstc 99/1985 (rtc 1985\99), 50/1990 (rtc 1990\50) y 149/1995 (rtc 1995\149), entre otras). Más recientemente lo ha reafirmado la stc 9/2005 de 17 enero en su fundamento jurídico 2.

${ }^{21}$ Incluso cuando hace referencia a las materias que pueden ser objeto de arbitraje, la ley de arbitraje de 2003 elimina como materias excluidas las señaladas en el anterior artículo 2.2 del rd 636/1993 que tantos problemas interpretativos habían provocado. Vid. Marín López, M.J., "La nueva regulación del arbitraje de consumo: Real decreto 231/2008, de 15 de febrero”, en Diario la Ley, núm. 6905, marzo 2008. 
llega exclusivamente hasta donde alcanza la libertad, que es su fundamento y motor y ese ámbito de libertad también tiene un respaldo constitucional, concretamente en el art. 33 CE, que reconoce el derecho a la propiedad privada, fundamentado en los postulados de la libertad económica y de la autonomía de la voluntad"22.

A pesar de ello, no podemos considerarlo como un principio absoluto puesto que, como ya hemos señalado, aunque las partes pretendan resolver sus controversias a través de este procedimiento extrajudicial de resolución de conflictos no todos podrán ser solucionados por medio de él. ${ }^{23}$ Por lo tanto, nos encontraremos ante materias indisponibles, como aquellas que giran en torno a los derechos fundamentales -la libertad, el honor, la seguridad, etc...-, aquellas sobre las que ha recaído ya sentencia judicial firme o las que traten sobre la filiación, tutela o incapacitación, entre otras. En la misma línea, el Convenio de Nueva York, al que España se adhirió en $1977^{24}$, limita la autonomía de la voluntad, en el sentido de establecer un control judicial sobre ésta -en concreto sobre la voluntad de las partes de pactar un convenio arbitral-, lo que constituye un elemento más de seguridad jurídica que supone el control judicial sobre la autonomía de la voluntad. De este modo, el párrafo 3 del artículo II del Convenio de Nueva York establece que: "El tribunal de uno de los estados contratantes al que se someta un litigio respecto del cual las partes hayan concluido un acuerdo en el sentido del presente artículo remitirá a las partes al arbitraje, a instancia de una de ellas, a menos que compruebe que dicho acuerdo es nulo, ineficaz o inaplicable. Es decir, corresponde a la jurisdicción estatal, a nuestros Jueces y Tribunales, comprobar que el convenio arbitral pueda ser nulo, ineficaz o inaplicable" 25 .

Dicho esto, la autonomía de la voluntad es un principio básico en el arbitraje. Nadie nos obliga a acudir al arbitraje, al menos en el ámbito del consumo, puesto que en los últimos meses se han aprobado algunos preceptos en los que el arbitraje, en este caso en materia laboral, será obligatorio para las partes. Me permito realizar un breve comentario a este respecto pues, aun tratándose de arbitraje en materia laboral y no de consumo, afecta de lleno al principio de autonomía de la voluntad, objeto principal de este trabajo. Es el caso del Real Decreto-ley 7/2011, de 10 de junio, de medidas urgentes

${ }^{22}$ Vid. Fernández Rozas, J.C., “Arbitraje y jurisdicción: una interacción..., cit., p. 59. de la misma opinión es Merino Merchán, para el que el "principio de autonomía de la voluntad enlaza con el ámbito de la libertad de cualquier ciudadano, de tal forma que los ciudadanos pueden resolver sus conflictos sin acudir a los órganos judiciales y tribunales". Vid. Estatuto y responsabilidad del árbitro. Ley 60/2003 de arbitraje. ed. Aranzadi 2004, p. 25

23 Sobre la limitación de la autonomía de la voluntad ha entendido O'Callaghan que "el principio de autonomía de la voluntad, sin embargo, no es absoluto, y el propio artículo 1255 enuncia límites, con un sentido muy general. en primer lugar, tiene límites extrínsecos que son a los que bace referencia la citada norma; las leyes, la moral y el orden público. en segundo lugar, tiene límites conceptuales, en el sentido de que las partes no pueden variar la naturaleza de las cosas ni subvertir los conceptos jurídicos; las partes no pueden, en ningún caso, desnaturalizar su concepto; no cabe que pacten una compraventa sin precio, o una donación a cambio de precio, o un comodato que transmita la propiedad, por ejemplo. en tercer lugar, tiene límites intrínsecos que es el caso del abuso del derecho y los derivados de los contratos de adbesión y de las condiciones generales de la contratación". Vid. O’Callaghan Muñoz, X.: Compendio de derecho civil. tomo 2 (obligaciones y contratos) vol.-1 enero 1993.

${ }^{24}$ Vid. instrumento de adhesión de España al convenio sobre reconocimiento y ejecución de sentencias arbitrales extranjeras, becho en Nueva York el 10 de junio de 1958. B.O.E. de 21 de junio de 1977.

${ }^{25}$ Vid. Convenio sobre reconocimiento y ejecución de sentencias arbitrales extranjeras, Nueva York, 10 de junio de 1958. 
para la reforma de la negociación colectiva, convalidado ya por el pleno del Congreso de los Diputados que impone el arbitraje, de forma obligatoria para ambas partes, para los casos en los que los convenios colectivos se bloqueen durante un periodo de tiempo determinado ${ }^{26}$. Esta norma viola de forma clara y rotunda unos de los principios básicos en torno al que gira la figura del arbitraje, la autonomía de la voluntad. No dudo de la buena intención de dicha norma, dotar de una mayor agilidad y dinamismo a la negociación colectiva, pero no es posible hacerlo a costa de imponer a las partes un arbitraje y violar la doctrina señalada por el Tribunal Constitucional, que señala la autonomía de la voluntad como esencia y fundamento del arbitraje ${ }^{27}$. Como señala acertadamente el profesor Cruz Villalón, el legislador "se equivoca cuando pretende imponer el procedimiento arbitral como obligatorio. Para empezar, la fórmula legal empleada por el real decreto ley traspasa las lineas rojas de la constitucionalidad. Conforme a la jurisprudencia constitucional, el arbitraje obligatorio impuesto desde la ley solo es admisible en casos excepcionales que no concurren en el caso previsto en esta ocasión" 28 . También el reciente Real Decreto Ley 3/2012, de 10 de febrero, de medidas urgentes para la reforma del mercado laboral ha incorporado una modificación del régimen del descuelgue para que, ante la falta de acuerdo y la no solución del conflicto por otras vías autónomas, las partes se sometan a un arbitraje. Así este Real Decreto Ley modifica el apartado 1 del artículo 86 del Texto Refundido de la Ley del Estatuto de los Trabajadores, aprobado por Real Decreto Legislativo 1/1995, de 24 de marzo, y establece que "en defecto de pacto específico sobre el carácter obligatorio o voluntario del sometimiento al procedimiento arbitral, se entenderá que el arbitraje tiene carácter obligatorio" 29.

${ }^{26}$ Señala el artículo 2.2 del real decreto que "en caso de desacuerdo durante el periodo de consultas, cualquiera de las partes podrá someter la discrepancia a la comisión paritaria del convenio, que dispondrá de un plazo máximo de siete días para pronunciarse, a contar desde que la discrepancia le fuera planteada. cuando aquella no alcanzara un acuerdo, las partes podrán recurrir a los procedimientos a que se refiere el siguiente párrafo". "Mediante los acuerdos interprofesionales de ámbito estatal o autonómico, previstos en el artículo 83 de la presente ley, se deberán establecer los procedimientos de aplicación general y directa para solventar de manera efectiva las discrepancias en la negociación de los acuerdos a que se refiere este apartado, incluido el compromiso previo de someter las discrepancias a un arbitraje vinculante, en cuyo caso el laudo arbitral tendrá la misma eficacia que los acuerdos en periodo de consultas y sólo será recurrible conforme al procedimiento y en base a los motivos establecidos en el artículo 91. dichos acuerdos interprofesionales deberán especificar los criterios y procedimientos de desarrollo del arbitraje, expresando en particular para el caso de imposibilidad de acuerdo en el seno de la comisión negociadora el carácter obligatorio o voluntario del sometimiento al procedimiento arbitral por las partes; en defecto de pacto específico sobre el carácter obligatorio o voluntario del sometimiento al procedimiento arbitral, se entenderá que el arbitraje tiene carácter obligatorio".

${ }^{27}$ A modo de anécdota se puede señalar que en nuestra historia preconstitucional sí que han existido situaciones en las que se ha impuesto la existencia de un arbitraje obligatorio, como las ordenanzas de Bilbao de 1737 que motivan el arbitraje "forzoso" entre los socios de la compañía mercantil con el argumento de evitar pleitos largos y costosos, capaces de arruinar a todos como la experiencia ha mostrado. Años más tarde las leyes que dieron lugar a la unificación del procedimiento arbitral mercantil y civil (decreto de refundición de fueros, de 7 de diciembre de 1868) disminuyeron el ámbito de la autonomía de la voluntad y remitieron a la ley de enjuiciamiento civil de 1881 la regulación del procedimiento arbitral. Estas leyes preveían el arbitraje societario con carácter obligatorio, postura que mantuvo la doctrina y la jurisprudencia (sentencias del tribunal supremo de 26 de abril de 1905 y 9 de julio de 1907), incluso tras su derogación, hasta mediados del siglo XX. Vid.: Merchan Álvarez, A.: El arbitraje. Estudio bistórico-jurídico, Sevilla 1981, pp. 147 y 356.

${ }^{28}$ Vid. Cruz Villalón, J., “Corregir el error”, en el diario El país, 13 de junio de 2011.

${ }^{29}$ Cfr. Artículo 14 seis del real decreto ley 3/2012, de 10 de febrero, de medidas urgentes para la reforma del mercado laboral. 
Retomando ahora el principio de autonomía de la voluntad en el ámbito del consumo, reitero que el arbitraje es opcional, no obligatorio. Luego si no existe voluntad por todas las partes implicadas, éste no tendrá sentido. Esta afirmación viene argumentada en distintas sentencias del Tribunal Constitucional, que reiteradamente señala que "la autonomía de la voluntad de las partes - de todas las partes-constituye la esencia y el fundamento de la institución arbitral, por cuanto que el arbitraje conlleva la exclusión de la vía judicial. Por tanto resulta contrario a la Constitución que la Ley suprima o prescinda de la voluntad de una de las partes para someter la controversia al arbitraje de la... La primera nota del derecho a la tutela consiste en la libre facultad que tiene el demandante para incoar el proceso y someter al demandado a los efectos del mismo"30. En la misma línea se había pronunciado con anterioridad el Tribunal Constitucional en la Sentencia de 23 de noviembre de 1995 al tratar el arbitraje obligatorio introducido por la Ley 16/1987, de 30 de julio, de Ordenación de los Transportes Terrestres. Dicha Ley establecía un arbitraje obligatorio para determinados casos siempre que no existiese un pacto en contrario expreso. El original artículo 38.2, párrafo primero, de la Ley 16/1987, de 30 de julio, de Ordenación de los Transportes Terrestres, al exigir un pacto expreso para evitar el arbitraje y acceder a la vía judicial, supeditaba "el ejercicio del derecho a la tutela judicial efectiva de una de las partes al consentimiento de la otra”. Este fue el argumento que utilizó el Tribunal Constitucional para declarar el artículo 38 contrario al artículo 24.1 de la Constitución. Aun si el arbitraje no se configuraba como obligatorio al $100 \%$ puesto que permitía pacto expreso en contrario, incluso en esta situación el Tribunal Constitucional señaló en su Sentencia de 23 de noviembre de 1995 que "...al hacerlo de forma que no pueda aludirse más que a través de un convenio entre todos los interesados, establece un impedimento para el acceso a la tutela judicial efectiva contrario al derecho de todas las personas a obtener la tutela efectiva de los jueces y tribunales en el ejercicio de sus derechos e intereses legítimos"”31.

La propia Ley de Arbitraje 60/2003 consagra a la autonomía de la voluntad como el principio más importante de este proceso al señalar en su exposición de motivos que "esta ley parte en la mayoría de sus reglas de que debe primar la autonomía de la voluntad de las partes" y que "la ley vuelve a partir del principio de autonomía de la voluntad y establece como únicos límites al mismo y a la actuación de los árbitros el derecho de defensa de las partes y el principio de igualdad, que se erigen en valores fundamentales del arbitraje como proceso que es. Garantizado el respeto a estas normas básicas, las reglas que sobre el procedimiento arbitral se establecen son dispositivas y resultan, por tanto, aplicables sólo si las partes nada han acordado directamente o por su aceptación de un arbitraje institucional o de un reglamento arbitral. De

${ }^{30}$ Sentencia del Tribunal Constitucional núm. 75/1996 de 30 abril rtc 199675; ponente: Excmo. sr. d. Pedro Cruz Villalón.

31 Aunque, como señala el propio Tribunal Constitucional “...No puede decirse, ciertamente que imponga un obstáculo arbitrario o caprichoso para acceder a la tutela judicial efectiva, pues responde, como destacan el fiscal general y el abogado del estado, a la plausible finalidad de fomentar el arbitraje como medio idóneo para, descargando a los órganos judiciales del trabajo que sobre ellos pesa, obtener una mayor agilidad a la solución de las controversias de menor cuantía" S.T.C. $174 / 1995$ de 23 de noviembre de 1995. 
este modo, las opciones de política jurídica que subyacen a estos preceptos quedan subordinadas siempre a la voluntad de las partes" 32 .

La Ley 60/2003 concede todo el poder a las partes, que podrán elegir a los árbitros y que determinarán, libremente, cómo ha de desarrollar el árbitro sus funciones decisorias que podrán estar basadas en el derecho, en la equidad o en reglas propias ${ }^{33}$. A pesar de esta afirmación, hemos de precisar que, una vez que las partes han accedido ya al arbitraje institucional, señala la profesora Cazorla González que "las partes tienen un ámbito de autonomía de la voluntad limitada, porque ello supone someterse al reglamento de la institución que lo administra, quedando el ámbito de libertad prácticamente reducido a decidir a qué Junta Arbitral presenta su solicitud de arbitraje de consumo, y sin posibilidad de dejar a las partes la facultad de decidir sobre el asunto (salvo que acepten la mediación previa, pues en esta fase su autonomía de la voluntad es amplia y flexible), ni tendrán facultad para autorizar a un tercero a que adopte una decisión acerca del conflicto que les afecta, como permite la Ley de arbitraje de $2003 " 34$.

Si bien esta Ley establece el arbitraje en equidad como excepcional, pues como señala su artículo 34.1 "los árbitros sólo decidirán en equidad si las partes les han autorizado expresamente para ello", en cambio el Real Decreto 231/2008 por el que se regula el Sistema Arbitral de Consumo en materia de consumo, si las partes nada acordasen de forma expresa a este precepto, regirá el arbitraje en equidad. Así lo recoge el artículo 25 del Real Decreto, "En la oferta pública de adbesión se expresará si se opta por que el arbitraje se resuelva en derecho o en equidad, así como, en su caso, el plazo de validez de la oferta y si se acepta la mediación previa al conocimiento del conflicto por los órganos arbitrales. En el supuesto de no constar cualquiera de estos extremos, la oferta se entenderá realizada en equidad, por tiempo indefinido y con aceptación de la mediación previa".

No podemos olvidar que el hecho de acudir de forma voluntaria a un arbitraje supondrá la renuncia unilateral de un derecho, cual es la exclusión voluntaria de la ley que habría de aplicarse, con los límites ya conocidos que hacen referencia a que no perjudique al orden público o a un tercero. Una precisión en este sentido, como señala el artículo 6.2 del Código Civil español, la exclusión voluntaria de la ley aplicable y la renuncia a los derechos en ella reconocidos solo serán validos cuando el derecho subjetivo aun no haya nacido, es decir que la renuncia por anticipado no será válida.

${ }^{32}$ Cfr. Preámbulo ley 60/2003 de arbitraje, boletín oficial del estado núm. 309, 26 de diciembre de 2003.

33 En la publicación de la escuela de organización industrial el arbitraje como forma de solución de conflictos empresariales, señalan que la "ley de arbitraje parte del principio de autonomía de voluntad de las partes, por lo que las normas relacionadas con el procedimiento arbitral son dispositivas y sólo se aplicarán en defecto de acuerdo entre las partes, acuerdo que puede ser directo o por su aceptación de un arbitraje institucional o de un reglamento arbitral". cfr. El arbitraje como forma de solución de conflictos empresariales, ed. EOI, 2005, p. 24.

${ }^{34}$ Vid. Cazorla González, M.J., "La mediación de consumo en el arbitraje institucional", 2009 workshop internacional sobre adr/odrs. construyendo puentes: marco jurídico y principios. Universitat Oberta de Catalunya (UOC), internet interdisciplinary institute (in3), 15 de septiembre de 2009. http://www.uoc.edu/symposia/ adr/ [artículo en línea]. 
En lo que hace referencia a la naturaleza jurídica, la aparente exclusividad jurisdiccional del Art. 117.3 CE no afecta a la constitucionalidad del arbitraje ${ }^{35}$. Así lo ha afirmado el Tribunal Constitucional en diversas sentencias: “...la naturaleza del arbitraje, que es un equivalente jurisdiccional, mediante el cual las partes pueden obtener los mismos objetivos que con la jurisdicción civil, esto es, la obtención de una decisión al conflicto con todos los efectos de la cosa juzgada" ${ }^{36}$. Ahondando en la materia, la Sentencia del Tribunal Constitucional 176/1996, de 11 de noviembre, a la que ya hemos hecho mención anteriormente, afirma que "... el derecho a la tutela judicial efectiva puede ejercitarse tanto en la jurisdicción ordinaria como mediante arbitraje. De manera que no cabe entender que, por el hecho de someter voluntariamente determinada cuestión litigiosa al arbitraje de un tercero, quede menoscabado y padezca el derecho a la tutela judicial efectiva que la Constitución reconoce a todos". En la misma línea, antes aun que las sentencias señaladas del Tribunal Constitucional, se manifestó el Tribunal Supremo en su Sentencia de 9 de octubre de 1989: “...no impide la igualmente facultad constitucional de optar para dicha tutela por el cauce extrajudicial del arbitraje”. En definitiva, como señala el Tribunal Constitucional, "la institución arbitral es compatible con la Constitución..." 37 A este respecto señala Hernández-Gil que "la Constitución, en la cúspide del ordenamiento, aun cuando no contenga una referencia explícita al arbitraje, sí debe habilitar la integración de la función arbitral, de configuración legal, en el seno de una más amplia función jurisdiccional orientada a la defensa de los Derechos subjetivos a la realización de la justicia y, en fin a la preservación de la tutela judicial efectiva mediante una diversidad de procedimientos de configuración legal que comprenden la regulación del arbitraje" 38 .

Eso sí, como ya hemos señalado, todo procedimiento arbitral ha de seguir los principios de igualdad, audiencia y contradicción ${ }^{39}$ que serán tutelados por los órganos judiciales a los que corresponda conocer la acción de anulación del laudo, o, llegado el caso, por el Tribunal Constitucional, frente a la resolución de la Audiencia Provincial que desestime la acción de nulidad cuando en el arbitraje se hubiese efectivamente vulnerado el derecho fundamental al proceso debido ${ }^{40}$. En el mismo sentido, y enmarcado igualmente en el propio proceso de arbitraje, es importante señalar un límite más al

35 Artículo 117 c.e.:

1. La justicia emana del pueblo y se administra en nombre del rey por jueces y magistrados integrantes del poder judicial, independientes, inamovibles, responsables y sometidos únicamente al imperio de la ley.

3. El ejercicio de la potestad jurisdiccional en todo tipo de procesos, juzgando y haciendo ejecutar lo juzgado, corresponde exclusivamente a los juzgados y tribunales determinados por las leyes, según las normas de competencia y procedimiento que las mismas establezcan.

36 S.T.C. 288/1993 de 4 de octubre de 1993.

${ }^{37}$ S. T. C. $174 / 1995$, de 23 de noviembre.

38 Cfr. Hernández-Gil Álvarez, Comentario a la ley de arbitraje, de Martín/Hierro (coord.), ed. Marcial Pons, Madrid, 2006, p. 40.

39 A este respecto afirma Díaz Alabart que "los principios básicos de todo arbitraje: igualdad, audiencia y contradicción, se conjug perfectamente con la nota de limitación de la autonomía de la voluntad de las partes que acabamos de ver, y la consiguiente uniformización de los procedimientos". Vid. Díaz Alabart, S., "El arbitraje de consumo y la nueva ley de arbitraje" en Actualidad civil, núm 11, junio 2005, p. 1285.

${ }^{40}$ Vid.: Cremades, B., "El arbitraje en la doctrina constitucional...", cit., p. 2. 
principio de autonomía de la voluntad de las partes -que debemos sumar a los ya mencionados- que no es prevalente respecto de la existencia de estas mínimas garantías a las que se debe el procedimiento arbitral a seguir en la sustanciación de las actuaciones arbitrales consideradas esenciales y que se ubican por encima de la autonomía de la voluntad de las partes ${ }^{41}$.

Pero no podemos obviar que la jurisdicción arbitral encuentra su fundamento en un negocio jurídico, el convenio arbitral, dirigido a la liquidación de una relación jurídica controvertida, de modo que la voluntad de las partes será la fuente del arbitraje. El profesor Xiol Ríos señala que "frente a posiciones iniciales que defendían el carácter del arbitraje como un equivalente jurisdiccional, la doctrina y jurisprudencia han ido evolucionando, subrayando la naturaleza contractual del arbitraje de sus orígenes, sin perjuicio de admitir el carácter jurisdiccional de sus efectos como elemento esencial de la institución dentro del marco legal" 42.

Por lo tanto hemos de señalar que existe una doble perspectiva y que será de naturaleza mixta ${ }^{43}$. Por un lado tendrá un carácter procesal, pues los efectos de cosa juzgada que produce un laudo arbitral no son discutibles ${ }^{44}$. Por otro tendrá naturaleza contractual, pues será necesaria la existencia de un convenio arbitral en el que expresamente las partes aceptan el arbitraje $\mathrm{e}^{45}$. En este mismo sentido el acto jurídico del que el arbitraje se deriva, sus facultades, sus funciones y la relación entre las partes se regulará en este convenio, que no deja de ser privado, y el lugar donde las partes podrán poner de manifiesto sus condiciones para resolver el conflicto ${ }^{46}$. Así, la esencia del arbitraje en orden a su

${ }^{41}$ Lorca Navarrete, A.M., "Las garantías del debido proceso de arbitraje”, en Diario la Ley, núm. 7111, febrero 2009.

${ }^{42}$ Señala como conclusión el presidente de la sala de lo civil del Tribunal Supremo que "la voluntad de las partes da lugar al nacimiento del arbitraje, pero los efectos ejecutivos del laudo no dependen directamente de la voluntad de las partes, sino de la propia naturaleza de la institución arbitral". Vid. Xiol Ríos, J. A., "El arbitraje y los tribunales de justicia”. Ponencia de 9 de febrero de 2007 en el Club español del arbitraje”, p. 11.

43 En la misma línea se manifiesta el profesor Cremades al afirmar que "entendiendo el tribunal constitucional que no existe una equiparación plena entre los órganos judiciales y los arbitrales, no puede mantenerse que la naturaleza del arbitraje sea puramente jurisdiccional, sino que nuestro derecho configura el arbitraje como una institución de origen contractual pero con efectos jurisdiccionales". Vid.: Cremades, B.: "El arbitraje en la doctrina constitucional...”, cit., p. 5. Del mismo modo Xiol Ríos señala que "el fundamento en la autonomía de la voluntad de la institución arbitral... no comporta, sin embargo, la exclusión del reconocimiento del carácter jurisdiccional del arbitraje en cuanto a sus efectos. Vid. Xiol Ríos, J. A., "El arbitraje y los tribunales...", cit., pp. 10 y 11.

${ }^{44}$ En este sentido, la institución del arbitraje en la Constitución de 1812 tenía una naturaleza marcadamente jurisdiccional ya que se enmarcaba en la sede normativa propia de los jueces y de la administración de justicia: concretamente, en el título V. De los tribunales y de la administración de justicia en lo civil y criminal. Como señala Merchan, "el lenguaje que se utiliza en la Constitución de Cádiz es claramente judicialista: el elemento dirimente se denomina jueces árbitros; la solución a la controversia, sentencia; y la reclamación sobre la misma, derecho de apelar”. Vid.: Merchan Álvarez, A., La jurisdicción arbitral..., cit., p. 135.

45 Establece el artículo 24 del real decreto 231/2008 sobre el convenio arbitral que "podrá adoptar la forma de cláusula incorporada a un contrato o de acuerdo independiente de las partes, deberá expresar la voluntad de las partes de resolver a través del sistema arbitral de consumo las controversias que puedan surgir o hayan surgido en una relación jurídica de consumo".

${ }^{46}$ Sobre las distintas teorías relativas a la naturaleza jurídica del arbitraje es muy interesante el análisis que realiza el profesor Bercovitz Rodríguez-Cano, "La teoría contractualista considera que el arbitraje es un contrato 
naturaleza viene conformada por la autonomía de la voluntad de las partes, que apertura el nacimiento del arbitraje, cuyos efectos dependen de la propia naturaleza del arbitraje, ya que la decisión arbitral plasmada en el laudo proviene del convenio arbitral al que las partes se han sometido expresamente ${ }^{47}$. Creo que es muy esclarecedora la Sentencia del Tribunal Supremo 776/2007, de 9 de julio, cuando afirma que "en la jurisprudencia constitucional se distingue con nitidez, por una parte, la actividad arbitral como relacionada con el principio de autonomía de la voluntad, pero regulada por la legalidad ordinaria al margen de la protección reforzada mediante el amparo del derecho a la tutela judicial efectiva que consagra el artículo 24 de la Constitución; y, por otra, la intervención judicial excepcional prevista en la LA, que constituye la única actividad jurisdiccional estatal propiamente dicha disciplinada por la regulación del expresado derecho a la tutela judicial, que tiene rango constitucional y formas reforzadas de protección mediante los recursos ante los tribunales ordinarios y recurso de amparo ante el Tribunal Constitucional" 48 .

\section{La Autonomía de la voluntad}

\section{EN LA MEDIACIÓN DE CONSUMO Y EL PAPEL DEL MEDIADOR}

Define el artículo 3.a de la Directiva 2008/52/CE del Parlamento Europeo y del Consejo, de 21 de mayo de 2008, sobre ciertos aspectos de la mediación en asuntos civiles y mercantiles a la mediación como "un procedimiento estructurado, sea cual sea su nombre o denominación, en el que dos o más partes en un litigio intentan voluntariamente alcanzar por sí mismas un acuerdo sobre la resolución de su litigio con la ayuda de un mediador". El Real Decreto 231/2008 dedica su artículo 38 a la mediación pero no llega a definirla en ningún caso, aunque sí que sienta los principios que deben regir en ella, como ahora veremos. El reciente Real Decreto Ley 5/2012, de 5 de marzo, de mediación en asuntos civiles y mercantiles, a pesar de que no sea de aplicación en el ámbito del consumo $^{49}$, define la mediación como "aquel medio de solución de controversias, cualquiera que sea su denominación, en que dos o más partes intentan voluntariamente alcanzar por sí mismas un acuerdo con la intervención de un mediador" ${ }^{50}$. Sobre lo que no hay duda alguna en la

por el que se delega en un tercero el arreglo de un litigio existente entre las partes de aquél”. Cfr. Bercovitz Rodríguez-Cano., Comentarios a la ley de arbitraje, Tecnos, Madrid, 1991, p. 18.

${ }^{47}$ Vid. Burgos Ladrón de Guevara, J.: “Naturaleza y ámbito del arbitraje en la ley 60/2003...”, cit., p. 4.

${ }^{48}$ Cfr. S.T.C., 776/2007, de 9 de julio, fundamento de derecho tercero.

49 Señala expresamente el real decreto ley 5/2012, de 5 de marzo, de mediación en asuntos civiles y mercantiles, que la mediación en materia de consumo queda excluida de su aplicación. Así, el artículo 2.2 de dicha ley, dedicado al ámbito de aplicación, establece que "quedan excluidos, en todo caso, del ámbito de aplicación de este real decreto-ley...d) la mediación en materia de consumo".

${ }^{50}$ Destaca Palao Moreno la importancia de la autonomía de la voluntad en el real decreto ley 5/2012, de 5 de marzo, de mediación en asuntos civiles y mercantiles al señalar que "la autonomía de la voluntad de la partes constituye, boy por hoy, un elemento fundamental en la gestión jurídica de las controversias internacionales en materia civil y mercantil". Palao Moreno, G., "Autonomía de la voluntad y mediación en conflictos transfronterizos en el real decreto ley 5/2012”, en Diario la Ley, núm. 7847. 
doctrina es que la mediación tiene como base, al igual que sucede en el arbitraje, a la autonomía de la voluntad de las partes implicadas en el conflicto ${ }^{51}$.

En los conflictos de consumo, como señala el profesor Maluque R., concurren una serie de connotaciones especialísimas, cual es, entre otras, el inicial desequilibrio entre las partes ${ }^{52}$. En este caso la autonomía de la voluntad de la que venimos hablando puede también quedar afectada por la existencia en una relación contractual de una posición de dominio de una de las partes respecto de la otra que obligue a un determinado procedimiento arbitral no querido ${ }^{53}$.

Cierto es que en la fase de arbitraje el árbitro decidirá en equidad o en derecho y actuará como garante para reparar esa desigualdad, pero ¿qué sucede en la fase previa de mediación? Es posible, y en mi experiencia como mediador me ha ocurrido en varias ocasiones, que, debido a la situación de inferioridad en la que en algunos casos se encuentra el consumidor, pueda renunciar a aquello que le corresponde en justicia a favor de aquel que se encuentra en una situación de superioridad ${ }^{54}$. En ese caso, ¿han los mediadores de permitir que se llegue a un acuerdo a cualquier precio? Cierto es que se tratará en todos los casos de materias disponibles para las partes pero también lo es que nos podemos encontrar en ciertos casos situaciones desesperadas en las que el consumidor esté dispuesto a aceptar cualquier acuerdo con tal de finalizar el proceso. A este respecto nos encontraremos con una parte - la más prepotente-que limita la autonomía de la más débil -el consumidor- pero, a su vez, la ley limita la autonomía de aquélla imponiéndole restricciones ${ }^{55}$, y esta situación puede entenderse como tal.

Pongo un ejemplo que me sucedió en una de las mediaciones que realizo: Una promotora construye un dúplex que, con todas las licencias correspondientes, vende a una pareja con dos hijos, uno de ellos recién nacido. Una vez instalados en el inmueble comienzan a aparecer, a través de cualquier hueco de la casa -luces, instalación de aire acondicionado, campana de la cocina, cuartos de baño...- cientos de cucarachas, haciendo imposible la habitabilidad del mismo. Una vez analizado el problema por la constructora se conviene que el problema ha sido que no se selló una fosa y que de ahí es de donde provienen las cucarachas. La promotora ofrece al matrimonio fumigar la casa -algo que

${ }^{51}$ Como afirma Cazorla González, "la autonomía de la voluntad de las partes es el núcleo fundamental a la hora de resolver un conflicto bajo cualquiera de las diferentes alternativas de resolución extrajudicial de conflictos, sobre todo en aquellas donde la solución la aportan ellos". Cfr. Cazorla González, M.J., "La mediación de consumo en el arbitraje... cit.

52 Vid. Maluquer Montes, C., "Oferta pública de sometimiento...” cit., pp. 126 y ss.

53 Vid. Fernández Rozas, J.C., “Arbitraje y jurisdicción: una interacción..., cit., p. 87.

${ }^{54}$ Un ejemplo de lo que sucede en casos de desigualdad en el ámbito laboral lo tenemos en el artículo 3 del estatuto de los trabajadores que, si bien no es extrapolable a la situación que se produce en materia de consumo sí que es interesante comprobar que cuando se refiere a los derechos y obligaciones concernientes a la relación laboral y aun en los casos en los que acuerden voluntariamente condiciones que sean menos favorables al trabajador, no serán válidas. Así señala este artículo que "por la voluntad de las partes, manifestada en el contrato de trabajo, siendo su objeto lícito y sin que en ningún caso puedan establecerse en perjuicio del trabajador condiciones menos favorables o contrarias a las disposiciones legales y convenios colectivos antes expresados".

55 Vid. Martínez de Aguirre, C., "Trascendencia del principio de protección a los consumidores en el derecho de obligaciones", en Anuario de derecho civil, 1994, p. 31. 
ya habían hecho con anterioridad ellos por cuenta propia- a sabiendas que es tan solo un pequeño parche que no solucionará, de forma definitiva, el problema de insalubridad. La pareja, no contenta con la oferta, acude a consumo y solicita un procedimiento de arbitraje. Sin duda la celeridad para este caso era fundamental, y el arbitraje la ofrecía. Una vez reunidas las partes con los mediadores, la oferta de la promotora no varió un ápice, pero en este caso la respuesta de la pareja fue distinta, aceptaron la oferta, sin duda, por la desesperación de tener que habitar en semejantes condiciones. Es obvio que el problema no se iba a resolver de forma definitiva. En estas circunstancias no me cabe duda de que, ya se tratase de un proceso judicial, ya fuese en el propio arbitraje -aplicando equidad o derecho- la sentencia o el laudo hubiera sido otro muy distinto, como mínimo la resolución definitiva del problema, la indemnización por tener que abandonar la casa durante unos días y la indemnización por daños y perjuicios morales. Pero, repito, la desesperación hizo que la pareja, con tal de solucionar de forma temporal el problema, aceptase una propuesta tan injusta. En este caso, a la pareja no le hubiera quedado más salida en un futuro que pedir la nulidad del procedimiento en base a lo recogido en el artículo 1817 del código civil "La transacción en que intervenga error, dolo, violencia o falsedad de documentos, está sujeta a lo dispuesto en el artículo 1.265 de este Código" 56. Aun así la decisión futura no sería, entiendo yo, muy halagüeña.

De ahí que surja una pregunta clave en torno a este respecto sobre la labor del mediador: ¿Debe ser el mediador un mero espectador neutral? Respecto a la imparcialidad no cabe duda alguna puesto que el mismo Real Decreto establece en su artículo 38.3 que "en todo caso, quien actúe como mediador en el procedimiento arbitral está sujeto en su actuación a los mismos requisitos de independencia, imparcialidad y confidencialidad exigidos a los árbitros". Pero a pesar de que, efectivamente, se exija la imparcialidad del mediador, en ningún caso se habla de neutralidad, que son conceptos distintos ${ }^{57}$. La neutralidad hace referencia a la relación del mediador con el resultado de la resolución de la controversia. Implica la imposibilidad de imponer un acuerdo determinado. La imparcialidad, en cambio, supone que en el cumplimiento de su encargo no puede confundirse con las partes. El mediador o mediadores han de ser ajenos al conflicto concreto en que actúan sin que puedan concurrir intereses personales o profesionales directos susceptibles de alterar o condicionar su actividad mediadora ${ }^{58}$. Es por eso que sostengo que la participación del mediador no solo puede ser activa, sino que debe de serlo. Como acabamos de ver, la legislación vigente en materia de consumo no supone obstáculo alguno puesto que

${ }^{56}$ Es sabido que el artículo 1.265 del Código Civil establece que "será nulo el consentimiento prestado por error, violencia, intimidación o dolo".

57 Tampoco lo hace la directiva 2008/52/, sobre ciertos aspectos de la mediación en asuntos civiles y mercantiles, la cual establece que "todo tercero a quien se pida que lleve a cabo una mediación de forma eficaz, imparcial y competente, independientemente de su denominación o profesión en el estado miembro en cuestión y del modo en que haya sido designado o se le haya solicitado que lleve a cabo la mediación".

${ }^{58}$ Santor Salcedo, H., La mediación en los conflictos de trabajo: naturaleza y régimen jurídico. Ed. La Ley, 2006, p. 148. 
impone la imparcialidad, y no la neutralidad ${ }^{59}$. Otros autores discrepan de la opinión que acabamos de manifestar, como Marín López, para el que "el mediador es un tercero, neutral e imparcial, que ayuda y guía a las partes involucradas en una situación conflictiva para que alcancen un acuerdo que sea mutuamente aceptable" 60 .

Por otro lado, y como soporte a la tesis que venimos defendiendo, señalan distintos autores y mediadores de consumo, que se han reconocido al mediador en este ámbito ciertas facultades que no ostenta en otros ámbitos de la mediación. Incluso podría llegarse al caso en el que el mediador realice una propuesta de solución al conflicto que las partes, obviamente, podrán libremente aceptar, rechazar o modificar ${ }^{61}$. Por eso mientras en la conciliación el conciliador actuará como mero testigo de la negociación de las partes, reduciendo su labor a velar porque los canales de comunicación permanezcan abiertos y las partes se respeten mutuamente, el mediador puede tener una participación más activa en la negociación, pudiendo organizar actividades para animar a las partes a obtener un consenso, incluso proponer una propuesta de solución ${ }^{62}$.

No se trataría tanto de orientar el resultado, sino de que los mediadores protejan los intereses de aquellos que se encuentran en una grave situación de desigualdad frente a la otra parte y les informen convenientemente. La fórmula que permitiría esta protección no es otra que la labor fundamental de información e incluso de asesoramiento, aunque éste sea más dudoso y criticado por algunos autores, que el mediador ha de realizar. A través de ésta tiene las herramientas necesarias para intentar evitar que ese desequilibrio genere un perjuicio grave e irreversible. Hemos de señalar que algunas actuaciones del mediador de consumo pueden encontrarse en la frontera de lo que la imparcialidad y neutralidad exigen, pero para los casos de evidente desequilibrio de los que venimos hablando se convierten en esenciales. Parte de la doctrina mantiene que la información que puede aportar el mediador no afecta a la imparcialidad pero que en cambio sí lo

59 Es necesario señalar aquí que la ley de mediación en asuntos civiles y mercantiles sí que incluye el principio de neutralidad entre los principios informadores de la mediación. De este modo, en su artículo 8 dice textualmente: "las actuaciones de mediación se desarrollarán de forma que permitan a las partes en conflicto alcanzar por sí mismas un acuerdo de mediación, actuando el mediador de acuerdo con lo dispuesto en el artículo 14". Pero como ya hemos señalado anteriormente, esta ley no es aplicable en el ámbito del consumo, lo que no obsta para tener en cuenta lo que señala sobre la neutralidad.

60 Ahonda este autor en esta opinión al manifestar que "la mediación constituye una forma de solución de conflictos, por medio de la cual son las propias partes las que consiguen poner fin a los mismos mediante un acuerdo adoptado tras una negociación en la que un tercero - el mediador-, intenta aproximar las posiciones o incluso proponer el acuerdo, pero sin que, en ningún caso, la solución al conflicto sea decidida ni impuesta a las partes por el mediador". Cfr. Marín López, M.J., "La nueva regulación del arbitraje..., cit., p. 15.

${ }^{61}$ Entre otros sostiene esta postura Blanco Carrasco que matiza al respecto lo siguiente: "esta actividad ha llevado a determinados sectores a considerar que la mediación es un sistema beterocompositivo, puesto que la solución se da por el tercero, si bien sin carácter vinculante. el que las partes puedan aceptar o rechazar la propuesta realizada supone un reconocimiento de la autonomía de la voluntad que ha permitido a algunos matizar su postura y considerar la mediación como un sistema heterocompositivo de menor medida o de bajo riesgo". Vid. Blanco Carrasco, M., "La alternativa de la mediación en conflictos de consumo: presente y futuro", en Anuario jurídico y económico escurialense, 2009, núm xlii.

${ }^{6}$ Vid. Ordeñana Gezuraga, I., "La mediación de consumo: la alternativa de la alternativa”, en Diario la Ley, núm, 7420, jun. 2010. 
hará el asesorar jurídicamente a las partes, "ya que mientras que las primeras -la información-conservan intacta la imparcialidad del mediador los consejos suponen una evaluación de las circunstancias particulares y la recomendación de una acción específica que pondría en peligro su imparcialidad respecto a las partes" ${ }^{63}$. Es más, una de las funciones del mediador deberá ser la de suplir los defectos de información jurídica del consumidor en muchos de sus derechos en materia de consumo ${ }^{64}$. En este sentido entiendo que la postura que venimos defendiendo en este trabajo no afecta a la neutralidad, puesto que el mediador no buscará orientar el acuerdo hacia sus propios valores, sino que pretende que las partes tengan todos los elementos de juicio necesarios para que puedan tomar una decisión que no sea perjudicial para sus intereses. Tampoco rompe el principio de autonomía de la voluntad de las partes, puesto que seguirán siendo éstas las que decidan -acepten, rechacen o modifiquen- sobre la solución. Es más, incluso esta labor de información y asesoramiento aportaría una mejor comprensión de la situación de la que se trate y su decisión sería más meditada y con mayor conocimiento.

Volviendo al caso que nos ocupaba, el de la vivienda invadida por cucarachas, los mediadores debían haber avisado a los consumidores de que en caso de aceptar la propuesta que le realizaba la promotora se produciría un menoscabo en sus derechos, aunque estos tuviesen carácter de dispositivos. Una vez tenida esa información las partes seguirían decidiendo, pero habrían tenido más elementos de juicio para tomar la decisión. La posibilidad de recomendar la continuación del proceso hasta llegar al momento del arbitraje hubiese sido otra salida.

\section{BIBLIOGRAFÍA}

Bercovitz Rodríguez-Cano, A., Comentarios a la Ley de Arbitraje, Tecnos, Madrid, 1991.

Blanco Carrasco, M., "La alternativa de la mediación en conflictos de consumo: presente y futuro", en Anuario Jurídico y Económico Escurialense, 2009, núm XLII.

Bonachera Villegas, R., "El Real Decreto 231/2008, la anhelada modificación del sistema arbitral de consumo" en Diario La Ley, núm. 7045, Octubre 2008.

Burgos Ladrón de Guevara, J., "Naturaleza y ámbito del arbitraje en la Ley 60/2003. Asistencia judicial del arbitraje”, en Diario la Ley, 2273/2007. Núm. 6745, Sección Doctrina, 28 Jun. 2007.

Cazorla González, M. J., "La mediación de consumo en el arbitraje institucional", 2009 Workshop Internacional sobre ADR/ODRs. Construyendo puentes: marco jurídico y principios. Universitat Oberta de Catalunya (UOC), Internet Interdisciplinary Institute (IN3), 15 de septiembre de 2009. http://www.uoc.edu/symposia/adr/ [artículo en línea].

Cremades, B., "Consolidación de la autonomía de la voluntad en España: El arbitral", Tratado de Derecho arbitral, Soto Coaguila, C.A. (Dir). Ed. Colección de Estudios, 2011.

${ }^{63}$ Vid. Requena, M., Propuestas del Consejo de Europa sobre formación y uso de la mediación. Jornadas de mediación para la ruptura de la pareja, ATYME, Madrid, septiembre 1999.

${ }^{64}$ Vid. Santás Seara, S., La mediación como herramienta de resolución de conflictos en materia de consumo. Supuestos prácticos, Mérida, 23, 24 y 25 de febrero, 2010. 
Cruz Villalón, J., "Corregir el error”, en el diario El País, 13 de junio de 2011.

De Castro, F., El negocio jurídico, Madrid, 1967.

Díaz Alabart, S., "El arbitraje de consumo y la nueva Ley de Arbitraje", en Actualidad Civil, núm 11, junio 2005.

FERNÁNDEZ RozAs, J. C., “Arbitraje y jurisdicción: una interacción necesaria para la realización de la justicia”, en Derecho Privado y Constitución, núm. 19, 2005.

Hernández-Gil Álvarez-Cienfuegos, A., Comentario a la Ley de Arbitraje. De Martín/Hierro (Coord.), Ed. Marcial Pons, Madrid 2006.

Lorca Navarrete, A. M., "Las garantías del debido proceso de arbitraje", en Diario La Ley, núm. 7111, febrero 2009.

Maluquer Montes, C., "Oferta pública de sometimiento al sistema arbitral", en Estudios sobre Consumo $\mathrm{N}^{\circ}$ 59, Madrid, 2001.

Marín López, M. J., "La nueva regulación del arbitraje de consumo: Real Decreto 231/2008, de 15 de febrero", en Diario La Ley, núm. 6905, marzo 2008.

Martínez de Aguirre, C., "Trascendencia del principio de protección a los consumidores en el Derecho de obligaciones", en Anuario de Derecho Civil, 1994.

Merchán Álvarez, A., "La jurisdicción arbitral en la Constitución de Cádiz", Materiales para el estudio de la Constitución de 1812, Cano Bueso, J., (ed.), Parlamento de Andalucía/Tecnos, Sevilla, 1989.

Merchán Álvarez, A., El arbitraje. Estudio histórico-jurídico, Sevilla 1981.

O’Callaghan Muñoz, X.: Compendio de Derecho Civil. Tomo 2 (Obligaciones y Contratos) vol. - 1 Enero 1993.

Ordeñana Gezuraga, I., "La mediación de consumo: la alternativa de la alternativa", en Diario La Ley, núm, 7420, Jun. 2010.

Otero Lastres, J. M., "El derecho fundamental a la tutela judicial efectiva" en Abogados, 2007.

Requena, M., Propuestas del Consejo de Europa sobre formación y uso de la mediación. Jornadas de mediación para la ruptura de la pareja, ATYME, Madrid, septiembre 1999.

Ruiz-Rico, J. J. y Contreras, M., “Artículo 51", en Comentarios a la Constitución española, Alzaga, O. (dir). EDERSA.

SANTÁs SEARa, S., La mediación como herramienta de resolución de conflictos en materia de consumo. Supuestos prácticos. Mérida, 23, 24 y 25 de febrero, 2010.

Santor Salcedo, H., La mediación en los conflictos de trabajo: naturaleza y régimen jurídico. Ed. La Ley, 2006.

Xiol Ríos, J. A., "El Arbitraje y los Tribunales de Justicia”. Ponencia de 9 de febrero de 2007 en el Club Español del Arbitraje. 
